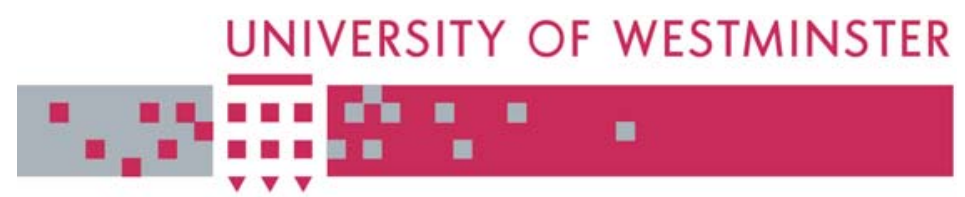

WestminsterResearch

http://www.westminster.ac.uk/westminsterresearch

\title{
The importance of real-world experience in student learning.
}

\author{
Bridgette Saunders ${ }^{1}$ \\ Radmila Juric ${ }^{2,3}$
}

${ }^{1}$ School of Informatics and Multimedia Technology, University of North London,

${ }^{2}$ South Bank University Business School

${ }^{3}$ Radmila Juric now works within the School of Informatics, University of Westminster

Copyright (C) [2001] IEEE. Reprinted from Kalpic, Damir and Dobric, Vesna Hljuz, (eds.) ITI 2001 : proceedings of the 23rd International Conference on Information Technology Interfaces : June 19-22, 2002, Pula, Croatia. IEEE, pp. 117-122. ISBN 9539676932.

This material is posted here with permission of the IEEE. Such permission of the IEEE does not in any way imply IEEE endorsement of any of the University of Westminster's products or services. Personal use of this material is permitted. However, permission to reprint/republish this material for advertising or promotional purposes or for creating new collective works for resale or redistribution to servers or lists, or to reuse any copyrighted component of this work in other works must be obtained from the IEEE. By choosing to view this document, you agree to all provisions of the copyright laws protecting it.

The WestminsterResearch online digital archive at the University of Westminster aims to make the research output of the University available to a wider audience. Copyright and Moral Rights remain with the authors and/or copyright owners.

Users are permitted to download and/or print one copy for non-commercial private study or research. Further distribution and any use of material from within this archive for profit-making enterprises or for commercial gain is strictly forbidden.

Whilst further distribution of specific materials from within this archive is forbidden, you may freely distribute the URL of WestminsterResearch (http://www.westminster.ac.uk/westminsterresearch).

In case of abuse or copyright appearing without permission e-mail wattsn@wmin.ac.uk. 


\title{
The Importance of Real-World Experience in Student Learning
}

\author{
Bridget Saunders ${ }^{1}$ and Radmila Juric ${ }^{2}$ \\ ${ }^{1}$ School of Informatics and Multimedia Technology, University of North London, \\ 120-166 Holloway Road, London N7 8DB \\ Tel: 0207973 4883, Fax: 0207793 7009, E-mail b.saunders@unl.ac.uk \\ ${ }^{2}$ Business School, South Bank University, 103 Borough Road, London SE1 0AA \\ Tel: 0207815 7888, Fax: 0207815 7793, E-mail juricr@sbu.ac.uk
}

\begin{abstract}
A core module for the computer science and computing degree courses at the University of North London provided a vehicle for developing an innovative approach in teaching and learning. It served as a means of bridging the gap between real-world Business Information Systems (BIS) development practice and that which is normally simulated in academia. We also show how students can be encouraged to be proactive in creating their own real-world learning experience within an academic environment.
\end{abstract}

Keywords: computing degree courses, BIS, assessment, student learning

\section{Introduction}

A pressing issue facing lecturers teaching in Higher Education today is bridging the gap between real world relevance and the academic vision (Saunders \& Georgiadou 1999a, 1999b).

Students need to be equipped to make an important and specific contribution to the workplace in order to be usefully employable when finishing their studies. Certainly, for some students their career aspirations are clear. However, for many, there is an obvious lack of confidence and no real belief that they will actually gain a foothold in the labour market, let alone any clear focus on the acquisition of a particular skills and knowledge set related to employability. Margaret Noble (Fry et al 1999) points out that "there is evidence to suggest that many students remain unaware of the development of employability skills and that "if, as a first step, students could identify them and where they acquired them, this would be significant progress in developing employability".

Educationalists are also committed to developing the students' intellectual powers of reasoning and creative thinking associated with the latest developments in a particular discipline. We want, if possible, to engender an interest in research whilst, encouraging students to develop a clear career focus.

The UK Government commissioned the Dearing Report on Higher Education published in 1997, which advocated "modernisation".

"Modernisation in relation to higher education means widening access to teaching and learning, particularly for young people from disadvantaged backgrounds, raising standards of research and teaching in order to compete in a global market, becoming more responsive to the needs of employers and the economy, exploiting new technologies and research" (Hodgson \& Spours 1999).

The UK universities have responded positively to the Government requirement to "widen access" despite the global market exerting hitherto unknown pressures on individual institutions. The student base has now broadened in terms of ability upon entry and academics are now 
confronting the challenge of many students needing additional support in both communications and numeracy in order to achieve the academic standards required..

Employers' needs are not being met and it is up to individual academics to introduce into their modules those elements relating to current employer expectations, appropriate new technologies and to identify potential research opportunities that exist within their disciplines.

This paper is a response to the issues associated with the gap that exists in various ways amongst all the parties above. Our response is to bring real-world experience into the academic arena through an innovative approach to teaching and assessment. Section 2 describes the teaching module in question with its conventional textbook learning approach. Section 3 bridges the gap mentioned earlier through prescribed assessment process and assessment instrument. Section 4 covers the total experience from both lecturer and student perspectives. We conclude in Section 5 by itemising all the lessons that we have learned.

\section{Module Background}

IM201 Systems Analysis and Design is a core module for the Computer Science and Computing Degree courses and an Option for the Joint Degrees shared with Business Information Systems or Multimedia at the School of Informatics and Multimedia Technology (SIMT) at the University of North London It belongs to the discipline of Business Information Systems (BIS) rather than Computer Science. It is, in fact, multi-disciplinary, and as the complexity and importance of BIS has grown, so the business community has recognised the need to adopt a more expansive development philosophy in order to compete successfully. Thus, this module is of particular interest to students wanting a career in business consultancy or systems analysis.

\subsection{Present Teaching Method}

It has regularly attracted around 250 students including those resitting. The student to tutor ratio is normally $24: 1$ resulting in about 10 tutors in all. In July 2000, the module was running efficiently by employing the web technology in a most effective and innovative way. There was a general commitment within SIMT's culture to "think smarter", utilising web technology to compensate for quite a serious shortage of staff and the very large number of students. Students used external websites to develop their coursework that could be viewed by the module convenor at any time. Coursework was also submitted electronically thus providing greater flexibility for students time management but, unfortunately, limiting the interaction with the module convenor.

The web technology was being used for communicating with students via both a module website and the convenor's website. The students had made a definite cultural shift to looking at the web for guidance with obvious benefits for those unable to attend the university. The, then, module convenor had a routine of placing his lecture notes on the website as he gave his lecture. All students therefore, had access to the breadth and depth of topics included in the module.

In July 2000 , assessment consisted of three elements, all aggregated with various weightings to represent one coursework and one final mark. The first two elements consisted of a choice of textbook based case studies, worked in groups of four and delivered in two parts. Part 1 (weighted 20\%) consisted of an online submission of some initial BIS modelling to provide a milestone for student feedback. Part 2 (weighted $45 \%$ ) represented the final project submitted in hard copy. The third element consisted of an on-line multi-choice test, which had caused some understandable technical problems with such a huge number of students all accessing the system at the same time.

\footnotetext{
$23^{\text {rd }}$ Int. Conf. Information Technology Interfaces ITI 2001, June 19-22, 2001, Pula, Croatia
} 


\section{Bridging the Learning Gap}

The author inherited the module from September 2000. Although fully appreciating the effective way in which web technology had been employed on this module,

i) it did not address students' lack of confidence;

ii) it did not address the relevance of their learning experience to their employability and further

iii) it had the potential to "distance" despite its immediacy in terms of response. In fact, the skills that the students need to acquire are dependent on continual guidance, encouragement and feedback;

iv) it lacked the potential for tutor involvement in the student learning process

The module syllabus was based on the tools and techniques employed by BIS developers but lacked the context of the BIS discipline in which real world issues and experience are explored: Further, in the real world, there is a long history of communication problems experienced between BIS developers and users. These communication problems cannot be experienced through a textbook case study so the appropriate skills will not be developed. Similarly, problems arise in trying to simulate the real world business context, such as the cost of time involved in interviewing, of capturing requirements and the tensions involved in working towards building a contract.

Earlier research (Saunders \& Georgiadou 1999a, 1999b) has revealed that employers within the BIS development community are critical of undergraduates, many of whom they perceive as lacking business acumen and initiative. They fear the "computer nerd" who constantly needs to be told what to do. There was also a clear "gap" between the experiences of real world developers and the academic vision that was being taught.

The challenge therefore, is threefold:

a. To raise awareness of, and to equip students with the appropriate knowledge and skills for employment

b. To reinforce the business context in which BIS development takes place

c. To develop the potential for creative and original thinking in problem solving

\subsection{The Assessment Process}

The assessment structure has been inherited with some limited opportunity for improvement:

(i) To introduce a real world case study which has the potential for providing a really comprehensive learning experience.

(ii) To devise assessment instruments that focus on the learning experience that the students must create for themselves.

(iii) To support tutors to engage with the students as facilitators rather than as teachers and to focus on the learning experience rather than the product.

A real world case study could provide insight into:

a. The communication problems that exist between all parties concerned in systems development and encourage students to adopt appropriately technical language when discussing BIS development issues with variously computer literate people. The onus will be on the student to clarify user understanding using terms and expressions that may not be familiar to them but are particular to the problem domain.

b. The analysis of a specific BIS in a particular business domain. This will require students to carry out some investigation of the business area and the status of a company of their choosing within

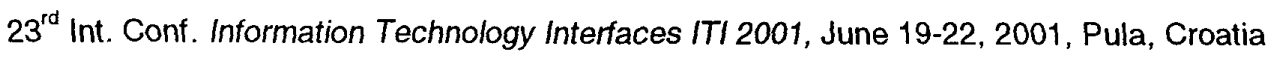


it, in order to create an acceptable or realistic model applying the latest and most appropriate technology. It should also encourage the development of research skills.

c. A team environment where knowledge and ideas regarding their experience can be freely expressed and shared with each other without fear of plagiarism. This spirit of co-operation is normal in a working environment. Students should learn from each other and transfer ideas whilst working on their own individual projects.

d. Business operating environment, offering students the opportunity for innovative problem solving and creative ideas. They should experience the "feel" of the business consultancy role. A project of this type, if fully developed, could provide a substantial addition to a student's portfolio.

There are problems however, in devising assessment criteria that:

(i) are truly fair. Richard Wakeford (Fry et al., 1999) points out that "to be effective, assessment will need to reflect programme content, and be valid, reliable and fair".

(ii) focus the effort on the experience rather than the product

(iii) measure creativity which is so much desired by employers;

(iv) measure the experience of one person against another

(v) measure the distance that an individual has travelled to arrive at a new idea

(vi) judge whether the idea is new or innovative to them as a young person when it may not be new to the assessor?

\subsection{The Assessment Instruments}

The coursework structure remains the same, assessed in three parts, the first two combining to produce the Project (with students working in teams of four), and the third being a time-constrained test. Students will work on their projects during tutorials with tutors acting as facilitators. The following paragraphs outline the coursework content and structure after changes.

Coursework 1 -This will be a structured walkthrough involving a presentation of the initial (analysis) stages of the Project to other project teams in order to elicit their ideas and constructive criticism. It will represent a milestone in week 6 providing immediate feedback from both the tutor and fellow teams. Students will not be marked on their presentation skills but on the (a) overall clarity of their presented project, (b) the research carried out into the business domain, on (c) the company itself, (d) the students' ability to correctly apply the techniques learned and (e) the appropriateness of their suggested solution.

Coursework 2 - The Final Project provides an opportunity for students to complete a set of tasks that constitute BIS development up to system specification and also to work with a team to a specific deadline.

There are four additional documents to be completed with the final coursework by individual students.

a. The Team Process Report provides an opportunity for team members to reflect on their team experience.

b. The Personal Reflection Sheet provides an opportunity for team members to reflect on their personal experience within the team and their career

c. A Peer Team' Review sheet may provide an opportunity for adjusting individual marks through peer assessment (Peer Review). This document is intended to encourage recognition of those students who are marginalized in a team or for those wishing to pay tribute to a particular member's contribution.

d. A Team Meeting Log where students can record progress and the individual distribution of responsibility.

$23^{\text {rd }}$ Int. Conf. Information Technology Interfaces ITI 2001, June 19-22, 2001, Pula, Croatia 
None of these documents from (a) to (d) above are part of the formal assessment but should focus the student on their learning experience during the learning period and in retrospect. The documents also offer tutors insight into their students' experience of the module and possibly of their own role in it. This approach is supported by Brown, Bull \& Pendlebury (1997) who stress "we include peer and self assessment as primary tools for learning rather than tools of summative assessment".

Coursework 3 -The final coursework constitutes a test, which is intended to test knowledge and understanding of all the topics covered during the module. It will be based on all aspects of the module and will consist of 20 short questions requiring answers of up to three lines of text. Revision plays an important part in reinforcing and contextualising all the topics learned throughout the module. It also serves to integrate the learning from theory and the practical work on the project.

\section{The Experience}

The demand for students to form teams of four and to find a case study for themselves meant, in effect, handing over a good deal of control to them. They chose to form their own groups and advised their names and ID's by email. It was then possible to allocate them a group number and use the website to allocate that group number to a tutor. This arrangement meant that the students had taken responsibility for their own project experience and there were clear signs that many were enjoying it.

There was always a possibility of students not finding a suitable case study which would have meant their having to do an alternative textbook based study. This would have resulted in two very different forms of assessment. However, the students would never be allowed to be disadvantaged and it was believed that the potential advantages to student development considerably outweighed the risk of having two different types of assessment.

In the event, the students' response was one hundred percent positive and only one group struggled to find a suitable system to analyse.

Coursework $I$ - Students carried out background research on the environment and the chosen company. They devised questionnaires and Rich Pictures (Checkland and Scholes, 1999) interviewed their client and produced an initial model which they presented to their teams in week 6 . They received immediate feedback from the tutor but few students were prepared to ask questions. The marking scheme was explained two weeks before the presentation and placed on the website

Coursework 2 - The Final Project required students to complete the BIS design from the model developed in Coursework 1. This presented assessment difficulties because of the varied business type and access opportunities that the students had experienced. The assessment focussed on (a) the students' ability to demonstrate how they had applied their learning to the task and (b) students' ideas of how their suggested system would benefit their client. The marking scheme was explained in week 6 and the students were asked for their response - whether they thought it was fair in terms of what was being marked and the distribution of marks.

Coursework 3 - The change from Multi-Choice to an In-Course Test was a worrying experience for many students. However, the project had, in fact, prepared the students for the questions in many respects and, as a result, the overall outcome was good.

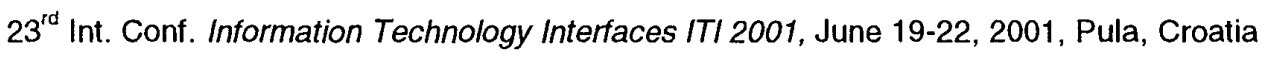




\section{The lessons learned!}

We conclude with the following:-

a. The structured walkthrough placed considerable responsibility and pressure on a individual tutors to listen, make constructive notes, give constructive feedback and allocate marks before moving onto the next presentation.

b. There was also no way of verifying the mark afterwards, particularly if the student was unhappy because the mark was not based on the materials or the students' presentation skills but on the content of their presentation. Brown, Bull and Pendlebury (1997) believe that "the most effective method of improving oral communication is through video feedback". In fact a video presentation (if it is possible to resource) would verify the students' performance as well as being a useful feedback mechanism whether or not the students are being assessed on presentation skills.

c. There are problems of subjective judgement when tutors have worked closely with students and this resulted in a rather generous allocation of marks that had to be readjusted quite harshly at the end. However, a marking scheme based on process learning always presents problems, particularly with such a large number of tutors. In future, therefore, a second lecturer should be present to balance the subjectivity and to verify the content of the work..

d. The main project (Coursework 2) became too time consuming for some students and needs to be more closely monitored by tutors so that a boundary is clearly drawn early on, around the area identified for initial BIS development. However, the additional documentation was helpful in allocating marks and possibly getting feedback from students. It is difficult to judge how useful these were in the student learning experience although most were completed to a good standard.

e. The Test (Coursework 3) was a very straightforward arrangement and students performed better than expected. Some students are known to have communications problems but the test had been designed to show examples of understanding and few questions expected much written response.

In conclusion, the assessment criteria were considered successful in that there was a much improved pass rate. Also the students engaged enthusiastically with the practical work. The overall standard of work was considered good and the tutors themselves were clearly enthusiastic about their role with the students. They felt very positive about the student experience and the knowledge and skills that were being gained as the module proceeded. Students were asked to complete a questionnaire on the Structured Walkthrough and the results of the final Course Evaluation questionnaire were also very positive, (151 were completed). Further comparative feedback will be sought from colleagues as the students' progress through other modules.

\section{References:}

1. Brown,G, Bull,J \& Pendlebury (1997) Assessing Student Learning in Higher Education, Routledge

2. Checkland, P, and Scholes, J (1999), Soft Systems Methodology in Action, John Wiley \& Sons

3. Hodgson H, and Spours S, (1999) New Labour's Educational Agenda: Issues and Policies for Education and Training from 14+, Kogan Page

4. Noble, M (1999) Teaching and Learning for Employability, A Handbook for Teaching and Learning in $H E$, Chapter 10; Kogan Page

5. Saunders, B, Georgiadou, E (1999a) “Awareness and Practice of Information Systems Development Methodologies in Business Today", in Proceedings of the Software Quality Management Symposium 1999, SIG Software Quality, British Computer Society

6. Saunders, B, Georgiadou, E (1999b) "Information Systems Development and the Need for the Multifacetted Manager", in proc. of INSPIRE IV Conference, SIG Software Quality, British Computer Society

7. Wakeford, R (1999) Principles of Assessment, A Handbook for Teaching and Learning in HE, Chapter no 5, Kogan Page 